\title{
Epidemiological aspects of Proteus infections with particular reference to phage typing
}

\author{
DIANA R. FRANCE ${ }^{1}$ AND N. P. MARKHAM \\ From the Department of Microbiology, University of Otago Medical School, Dunedin, New Zealand
}

SYNOPSIS The properties and characteristics of 296 Proteus strains isolated from hospital patients and from sewage have been examined with a view to determining those characters which are of most use in following and detecting cross-infection.

Ninety-six per cent of the organisms isolated were $P$. mirabilis and it was found that by identifying biotypes and by phage typing the species could be divided into a relatively large number of groups which would be useful for epidemiological investigation.

Organisms of the genus Proteus may be found in the intestines of normal individuals and are widely disseminated through human communities. They may function as primary as well as secondary pathogens and their incidence in infected burns and wounds has increased in recent years. In urinary tract infections they often replace the primary pathogen following antibiotic therapy.

The aim of this study has been to assess the incidence of Proteus infections in a metropolitan hospital and to determine characteristics of strains which might be useful in tracing the source of hospital cross-infection. It has yet to be proved whether hospital cross-infection or auto-infection from the gut is the most important method of infection. In the past, serological typing and the use of the Dienes phenomenon (Dienes, 1946) have been used for epidemiological purposes, but neither method has been very satisfactory. An additional and more reliable method is required and in this study attention has been paid to the possible value of phage typing Proteus strains.

\section{MATERIALS AND METHODS}

SOURCES OF STRAINS During nine months of 1964, 296 Proteus strains were obtained from clinical specimens from hospital patients or from sewage. Of the hospital strains 248 were from in-patients and 23 from outpatients of a 500-bed hospital. The majority of organisms were isolated from urine and faeces and smaller numbers from pus, nasal, or wound swabs and blood cultures. The 48 strains isolated from sewage were the only Proteus strains obtained from an examination of 96 samples.

Received for publication 8 June 1967.

'Present address: National Health Institute, Riddiford Street, Wellington, New Zealand.
In a case where more than one strain was obtained from the same patient, only strains which differed from the original in biochemical and cultural characteristics were included for subsequent examination.

IDENTIFICATION OF SPECIES Hydrolysis of urea on Christensen's medium and the conversion of phenylalanine to phenylpyruvic acid (Hill, Fung, and Marcus, 1962), were used as criteria to place non-lactose fermenting Gram-negative rods in the genus Proteus. Species identification was made on the basis of indole and $\mathrm{H}_{2} \mathrm{~S}$ production, liquefaction of gelatine, and the fermentation of glucose, lactose, maltose, mannitol, and sucrose (Table I).

TABLE I

IDENTIFICATION OF PROTEUS SPECIES

Substrate or Pr. vulgaris Pr. mirabilis Pr. morganii Pr. rettgeri Test

\begin{tabular}{|c|c|c|c|c|}
\hline Phenylalanine & + & + & + & + \\
\hline $\begin{array}{l}\text { Urea } \\
\text { hydrolysed }\end{array}$ & + & + & + & + \\
\hline $\begin{array}{l}\text { Lactose } \\
\text { fermentation }\end{array}$ & - & - & - & 一 \\
\hline $\begin{array}{l}\text { Sucrose } \\
\text { fermentation }\end{array}$ & + & + or - & - & - \\
\hline $\begin{array}{l}\text { Mannitol } \\
\text { fermentation }\end{array}$ & - & - & - & + \\
\hline $\begin{array}{l}\text { Maltose } \\
\text { fermentation }\end{array}$ & + & - & - & - \\
\hline $\begin{array}{l}\text { Glucose } \\
\text { fermentation }\end{array}$ & + & + & + & + \\
\hline Indole & + & - or + & + & + \\
\hline $\begin{array}{l}\text { Gelatin } \\
\mathrm{H}_{2} \mathrm{~S}\end{array}$ & $\begin{array}{l}+ \\
+\end{array}$ & + & $\overline{+}$ & - \\
\hline
\end{tabular}

BIOTYPES Differentiation of strains of Pr. mirabilis into biotypes was based on differences in the fermentation of sucrose and the production of indole. 
ANTIBIOTIC SENSITIVITY A standard inoculum of the test strain was spread in a zone at the periphery of a plate of Muller-Hinton medium. Antibiotic discs were placed at the inner edge of the zone and a known sensitive staphyloccocal strain was streaked from the centre of the plate to each disc to control its potency. The sensitivity of strains to penicillin, streptomycin, tetracycline, chloramphenicol, sulphafurazole, erythromycin, and nalidixic acid, was determined in this way.

DIENES PHENOMENON Identity of flagellar antigens was tested by the Dienes phenomenon (Dienes, 1946; Story, 1954). Organisms in phase A (Belyavin, 1951) were tested on nutrient agar plates incubated at $37^{\circ} \mathrm{C}$ overnight.

ISOLATION OF PHAGE These were isolated from lysogenic strains and 'from sewage. The method of Popovici and Ghioni (1962) was the most satisfactory. Phage was obtained from the supernatant of centrifuged broth cultures which had previously been incubated at $37^{\circ} \mathrm{C}$. for 24 hours and left at room temperature for a further 48 hours. Twelve phages were obtained by this method. A further eight phages were isolated from sewage supernatants, but these were the only phages obtained from 58 samples.

PROPAGATION OF PHAGE Strains used for phage propagation were selected by their sensitivity to the action of specific phage.

The soft agar layer (Adams, 1950) and the surface lawn (Blair and Carr, 1953) methods were used to propagate phage. Both gave high titre suspensions and were superior to the cellophane method (Liu, 1958).

Purification was achieved by freezing the lysate at $-18^{\circ} \mathrm{C}$. for 18 hours and thawing, a process which was repeated a second time before final centrifugation. The lysate was stored at $-18^{\circ} \mathrm{C}$. while dilutions were kept at $4^{\circ} \mathrm{C}$.

A set of 20 phages showing stability of lytic spectrum was chosen from a greater number and used for typing.

PHAGE TYPING Phage activity was tested by spotting phage suspension on a surface lawn on a nutrient agar plate. The lawn was prepared by flooding the agar with a three-hour broth culture grown at $37^{\circ} \mathrm{C}$. or with a 1 in 10 dilution of the suspension of growth washed from the surface of a nutrient agar slope with $10 \mathrm{ml}$. of broth. The seeded plates were dried at $37^{\circ} \mathrm{C}$. for 30 to 45 minutes. The phage preparations were then applied and the plates incubated for four to six hours at $37^{\circ} \mathrm{C}$. followed by overnight storage at $4^{\circ} \mathrm{C}$.

Phage suspensions were standardized, using the above method, to a routine test dilution which was that dilution of phage suspension which just failed to give confluent $\frac{\overrightarrow{0}}{\overrightarrow{0}}$ lysis on the propagating strain. The routine test dilution $\Rightarrow$ for the 20 phages in the set lay between $10^{-3}$ and $10^{-7}$. The lytic spectrum of each phage on all propagatingo strains was also determined.

In typing the production of 50 or more plaques by $a \overline{\bar{c}}$ phage suspension at routine test dilution was regarded $\vec{\Phi}$ as positive. Strains which did not react at routine test $\varrho$ dilution were re-tested at $1,000 \times$ routine test dilution.

\section{RESULTS}

PROTEUS SPECIES The species identified and their끙 source are shown in Table II from which it can be seen that $96 \%$ were Proteus mirabilis, $4 \%$ Proteus vulgaris, while a single strain of Proteus morganii was $\overrightarrow{0}$ isolated. More strains were obtained from urine samples than from any other material.

TABLE II

SOURCE AND NUMBER OF PROTEUS SPECIES ISOLATED

\begin{tabular}{|c|c|c|c|c|}
\hline Source & $\begin{array}{l}\text { Total } \\
\text { Isolated }\end{array}$ & Pr. mirabilis & Pr. vulgaris & Pr. morganii \\
\hline \multirow{6}{*}{$\begin{array}{l}\text { Urine } \\
\text { Wound } \\
\text { swabs, etc. } \\
\text { Nose } \\
\text { Faecal } \\
\text { Skin and feet } \\
\text { Sewage }\end{array}$} & 134 & 129 & 4 & 1 \\
\hline & 23 & 23 & 0 & 0 \\
\hline & 14 & 14 & 0 & 0 \\
\hline & 66 & 59 & 7 & $\mathbf{0}$ \\
\hline & 11 & 11 & 0 & 0 \\
\hline & 48 & 47 & 1 & 0 \\
\hline Total & 296 & $283(96 \%)$ & $12(4 \%)$ & 1 \\
\hline
\end{tabular}

BIOTYPES Division of strains biochemically ena bled $\stackrel{\overrightarrow{0}}{\vec{a}}$ four biotypes to be recognized. The majority of strains $(56.5 \%)$ were placed within biotype $1 \frac{F}{0}$ (Table III).

TABLE III

DIVISION OF STRAINS OF PR. MIRABILIS INTO BIOTYPES

\begin{tabular}{|c|c|c|c|c|}
\hline Test & Biotype 1 & Biotype 2 & Biotype 3 & Biotype 4 \\
\hline $\begin{array}{l}\text { Indole } \\
\text { Sucrose }\end{array}$ & $\begin{array}{l}\text { Negative } \\
\text { (AG;1 }\end{array}$ & $\begin{array}{l}\text { Negative } \\
\text { Negative }\end{array}$ & $\begin{array}{l}\text { Positive } \\
\text { (AG) }\end{array}$ & $\begin{array}{l}\text { Positive } \\
\text { Negative }\end{array}$ \\
\hline $\begin{array}{l}\text { Total } \\
\text { number }\end{array}$ & 160 & 113 & 4 & 6 \\
\hline
\end{tabular}

${ }^{1}(\mathrm{AG})=$ delayed acid and gas production

ANTIBIOTIC SENSITIVITIES The results are presented in Table IV. All strains were susceptible to nalidixic acid and most strains were susceptible to strepto-cmycin, chloramphenicol, and sulphafurazole.

TABLE IV

PERCENTAGE SUSCEPTIBILITY OF STRAINS OF PR. MIRABILIS TO ANTIBIOTICS

\begin{tabular}{|c|c|c|c|c|c|c|c|c|}
\hline Source & No. of Strains & Penicillin & Streptomycin & Tetracycline & $\begin{array}{l}\text { Chloram- } \\
\text { phenicol }\end{array}$ & Sulphafurazole & Erythromycin & Nalidixic Acid \\
\hline $\begin{array}{l}\text { Inpatient strains } \\
\text { Outpatient } \\
\text { strains }\end{array}$ & $\begin{array}{r}213 \\
23\end{array}$ & $\begin{array}{l}44 \\
83\end{array}$ & $\begin{array}{r}94 \\
100\end{array}$ & $\begin{array}{r}12 \\
0\end{array}$ & $\begin{array}{l}95 \\
83\end{array}$ & $\begin{array}{l}79 \\
98\end{array}$ & $\begin{array}{l}5 \\
0\end{array}$ & $\begin{array}{l}100 \\
100\end{array}$ \\
\hline Sewage & 47 & 43 & 100 & 9 & 98 & 58 & 0 & 100 \\
\hline
\end{tabular}

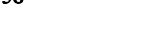


DiEnes PHenomenon When a Proteus strain was isolated from the rectal swab of a patient who had this organism elsewhere on the body, the paired strains were compared. Of the 63 pairs tested by the Dienes phenomenon, $91 \%$ showed noline of demarcation during swarming of pairs on a common plate and it can be assumed that these pairs shared a major flagellar antigen.

Using the same criterion it was found that multiple strains from a single patient, that is, those strains isolated from various sources at different times, and strains isolated from other patients in the same ward, often had similar flagellar antigens but these organisms sometimes had different phage types.

PHAGE TYPING Typing was carried out on 229 strains comprising 170 from hospital patients and 59 strains from other sources. It was found that $174(76 \%)$ strains were lysed by one or more phages of the set at routine test dilution, $13(6 \%)$ typed only at $1,000 \times$ routine test dilution, and $36(18 \%)$ were untypable. Many of the phages lysed $\boldsymbol{P}$. vulgaris as well as Pr. mirabilis.

The usefulness was assessed of the various phages in the typing set for epidemiological work. For this purpose the method of analysis employed by Davidson (1961) was used, and results which applied to the 170 hospital strains are shown in Figure 1. This shows the number of cultures lysed by each phage and the proportion of those cultures which were also lysed by each of the other phages. Thus phage 4 lysed 108 of the 170 cultures and $96(90 \%)$ of these 108 cultures were also lysed by phage 7 , but only $29(27 \%)$ were lysed by phage 6 . The heights of the columns in Fig. 1 are proportional to these percentages.

The lytic patterns fell into eight main groups with a further two patterns which were produced by a mixture of groups I and II and groups I and III phages (Table V).

Thirty strains were tested for stability of phage
TABLE V

PHAGE PATTERN OF TYPING GROUPS

\begin{tabular}{ll} 
Typing Group & Phage Pattern \\
\hline I & $4 / 7 / 11 / 14 / 19 / 20 / 23 / 24 / 25$ \\
II & $2 / 6 / 9 / 21$ \\
III & $18 / 23 / 24$ \\
IV & $1 / 15 / 16$ \\
V & 19 \\
VI & $19 / 20 / 23 / 25$ \\
VII & $2 / 6 / 15 / 22$ \\
VIII & $1 / 7 / 11 / 14 / 20$ \\
I-II & $2 / 4 / 6 / 7 / 9 / 11 / 14 / 19 / 20 / 21 / 23 / 24 / 25$ \\
I-III & $4 / 7 / 11 / 14 / 18 / 19 / 20 / 23 / 24 / 25$
\end{tabular}

type and checked after a period of six weeks at which time no significant alteration in the phage pattern was found.

The distribution of phage types in 170 hospital strains in relation to source and species and biotypes is given in Table VI. It can be seen that although some of the phage groups contained a moderately high proportion of strains, further subdivision of these could be made when the biotype had been determined.

Typing was also carried out on 55 strains isolated from repeat specimens from the same number of patients. Only three of these strains gave a phage typing pattern different from the original strain isolated.

During the course of study it became apparent that in two hospital wards cross-infection with Proteus strains had probably taken place. In one ward identical strains of Pr. mirabilis (phage group 3 , biotype 1) were isolated from four patients, three of whom had been catheterized. This particular phage type had not been encountered in this ward before the initial infection. The Dienes phenomenon could not be used in this circumstance because of the morphological state of the cultures. In a geriatric ward, 15 strains of Pr. mirabilis (phage group I-II, biotype 1 and each antigenically related as shown by Dienes phenomenon) were isolated from the urines of as many patients. Proteus strains isolated

TABLE VI

DISTRIBUTION OF PHAGE TYPES IN HOSPITAL STRAINS

\begin{tabular}{|c|c|c|c|c|c|c|c|c|c|c|}
\hline \multirow[t]{2}{*}{ Group } & \multicolumn{4}{|l|}{ Source } & \multicolumn{4}{|c|}{ Pr. mirabilis Biotypes } & \multirow[t]{2}{*}{ Pr. vulgaris } & \multirow{2}{*}{$\begin{array}{l}\text { Total } \\
\text { No. }\end{array}$} \\
\hline & Urine & Swabs & Nose & Faecal & 1 & 2 & 3 & 4 & & \\
\hline I & 31 & 6 & 1 & 13 & 33 & 13 & 1 & 1 & 3 & $51(30 \%)$ \\
\hline II & 8 & 2 & $\mathbf{0}$ & 7 & 10 & 7 & $\mathbf{0}$ & 0 & $\mathbf{0}$ & $17(10) \%$ \\
\hline III & 7 & 0 & $\mathbf{0}$ & 2 & 7 & 1 & 1 & 0 & $\mathbf{0}$ & $9(5 \%)$ \\
\hline IV & 1 & 1 & $\mathbf{0}$ & 0 & $\mathbf{0}$ & 0 & 1 & 0 & 1 & $2(1 \%)$ \\
\hline V & 4 & $\mathbf{0}$ & 0 & 4 & 5 & 3 & $\mathbf{0}$ & 0 & 0 & $8(5 \%)$ \\
\hline VI & 4 & 0 & 0 & 1 & 4 & 0 & 0 & 0 & 1 & $5(3 \%)$ \\
\hline VII & 2 & 0 & 0 & 1 & 1 & 2 & 0 & 0 & 0 & $3(2 \%)$ \\
\hline VIII & 2 & 0 & 0 & 0 & 1 & $\overline{1}$ & 0 & 0 & 0 & $2(1 \%)$ \\
\hline I-II & 17 & 3 & 2 & 12 & 16 & 18 & 0 & 0 & 0 & $34(20 \%)$ \\
\hline I-III & 1 & 2 & 0 & 2 & 2 & 2 & 1 & 0 & 0 & $5(3 \%)$ \\
\hline N.T. & 21 & 3 & 1 & 9 & 18 & $1 \overline{3}$ & 0 & 0 & 3 & $34(20 \%)$ \\
\hline
\end{tabular}




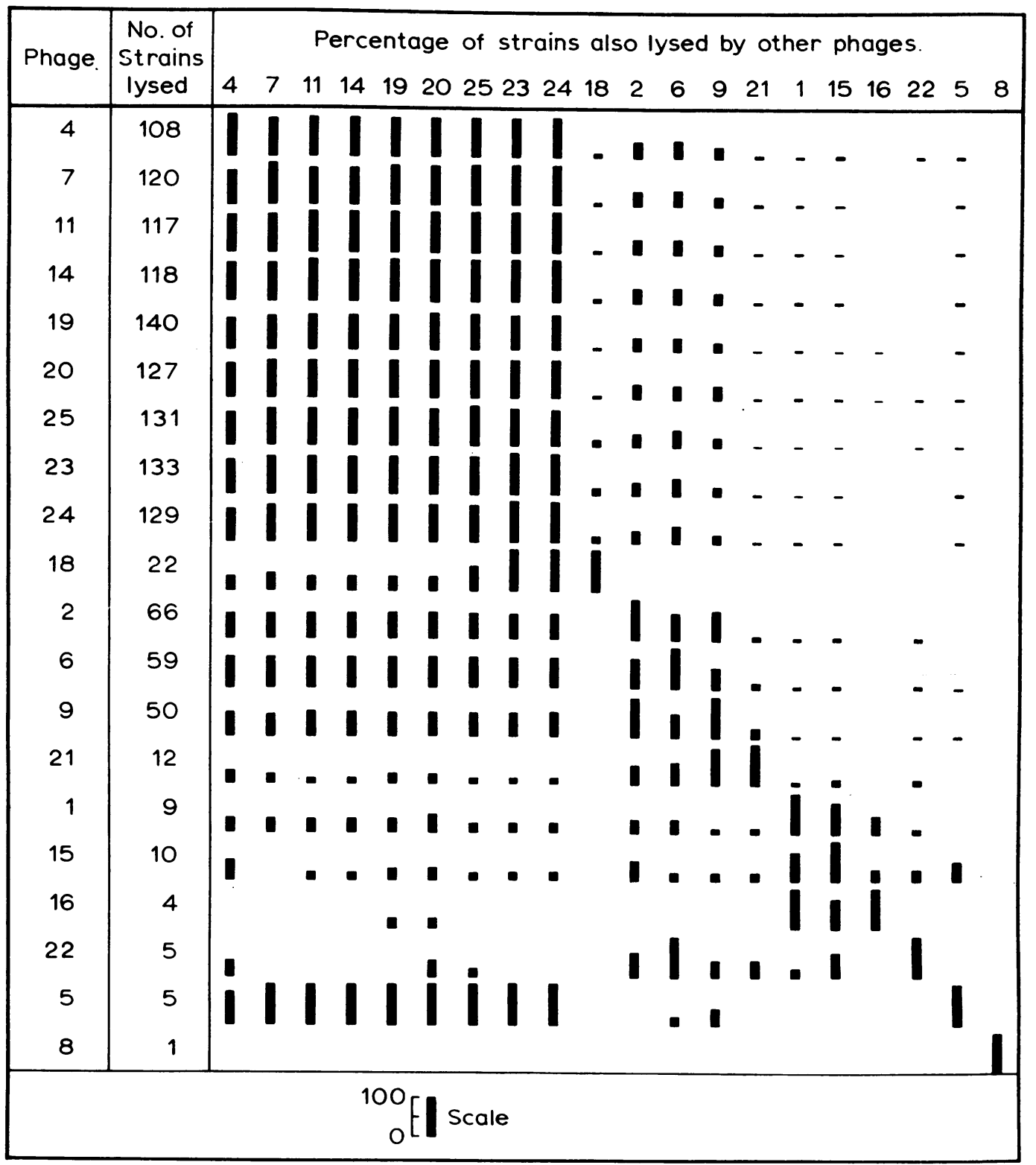

FIG. 1. Analysis of the phage patterns of 170 strains of Proteus from hospital sources to determine the frequency with which the phages are associated with one another.

from rectal swabs of six of these patients all differed in phage type and biotype from the urine strains although in one instance there was antigenic similarity.

\section{DISCUSSION}

The predominance of the species Pr. mirabilis $196 \%$ of 296 strains) amongst Proteus strains isolated from various sources is similar to the findings of others. Ten articles published between 1928 and 0 1964 all indicated the high incidences of this species $\overrightarrow{\mathbb{D}}$ which usually constituted $70 \%$ or more of the $\frac{?}{\mathbb{D}}$ collections of strains examined. As in the present $\stackrel{\varrho}{-}$ study $\boldsymbol{P r}$. vulgaris had the next highest incidence 
while Pr. morganii and Pr. rettgeri were either rare or absent. The failure to isolate the latter two species from the samples of sewage examined here is additional evidence of the rarity of these organisms in the human population.

On the basis of indole production and sucrose fermentation it was possible to divide strains of Pr. mirabilis into four biotypes. Of these, biotype 1 could be regarded as typical of the species and $56 \%$ were of this type. Biotype 2 was next in frequency (40\% of strains) and was the type most frequently found in a study made by Milner (1963). Biotypes 3 and 4 corresponded to the 'atypical 2' strains described by Kippax (1957) and together made up the remaining $4 \%$ of strains.

The majority of strains were sensitive to streptomycin, chloramphenicol, sulphafurazole, and nalidixic acid and resistant to penicillin, tetracycline, and erythromycin.

These observations agree with those made by Story (1954) but differ from the results of Eisenberg, Weiss, and Flippin (1958). The sensitivity of all strains to nalidixic acid is in accordance with the results of Ward-McQuaid, Jichlinski, and Macis (1963) and Lishman and Swinney (1963).

The use and acceptance of the Dienes phenomenon for the typing of strains has been varied. The test makes use of similarities in ' $H$ ' antigens, and Storey (1954) concluded that if strains did not intermingle it was strongly suggestive that they were different but that the reverse was not necessarily true. The Dienes phenomenon has been used in epidemiological studies but in general the identification of strains by this method has been unreliable. The results in this study were equivocal and the tests often difficult to read.

Because of the prevalence of Proteus infections in hospitals it is desirable to have a satisfactory method to identify strains which may be responsible for cross-infection. In most situations strains of Pr. mirabilis predominate and species identification will be of limited epidemiological value. The determination of biotypes of Pr. mirabilis is of limited value also since the majority of strains will be in one or other of two of the four types. The antibiotic sensitivity patterns of strains will depend on the extent to which the use of the various drugs has either selected resistant mutants or promoted the transfer of the resistance factors from other members of the Enterobacteriaceae. Antibiotic resistance patterns cannot therefore be used to identify a specific strain. The Dienes phenomenon at best identifies only major flagellar antigens and has no reference to somatic antigens. Perch (1948) was able to divide 536 strains into 98 serotypes by the identification of somatic and flagellar antigens. Sero- logical identification would be very satisfactory but is not practical for use in a routine laboratory because of the wide range of antisera required.

It seemed that phage typing might help in solving the problem of strain identification. We have found that $81 \%$ of the 229 strains (including 221 strains of $P r$. mirabilis and eight strains of Pr. vulgaris) were lysed by one or more of the 20 phages used. The phage patterns observed were stable in all of 30 strains tested. These results were comparable with those reported by Pavlatou, Hassikou-Kaklamani, and Zantioti (1965), who used 15 phages to divide 213 strains into 14 lysotypes. A retrospective analysis of our results showed that six phages were closely related and could be removed from the set without disadvantage thus leaving 14 phages (viz., 1, 2, 5, 7, 8, 9, 15, 16, 18, 19, 20, 21, 22, $23)$ to divide strains into eight typing groups. During the time when the lytic property of these phages on various strains was being investigated it was observed that cross-infection had occurred in two hospital wards due to Pr. mirabilis.

All strains from both wards were of the same biotype but the phage group was distinctive for strains from each ward. Antigenic similarity of strains from one ward could not be determined but strains isolated from the other were shown to have related antigens as determined by the Dienes phenomenon. Thus Proteus strains involved in two epidemic episodes were broadly grouped by biotype and specifically identified by phage grouping, while some additional evidence of similarity was provided by the Dienes phenomenon.

It is a reasonable assumption that infections in two wards were due to cross-infections caused by specific Proteus strains. If auto-infection from the patient's gut had been the predominant cause it would be expected that a variety of strains would have been involved. Sporadic cases of infection have been encountered where the faecal strain has been identical with the lesion strain but since faecal swabs were not taken before the lesion was manifest the significance of these observations is equivocal. In order to determine the incidence of autoinfection it would be necessary to identify faecal Proteus strains at the time of the patient's admission to hospital and before any lesion had been established.

It is concluded that phage typing of strains of Proteus can be useful for epidemiological purposes when it is supplemented by species and biotype determination.

We are very grateful to Professor J. A. R. Miles for allowing us to undertake this study and to AssociateProfessor M. J. Marples for advice and encouragement received during this investigation. 
REFERENCES

Adams, M. H. (1950). Meth. med. Res., 2, 1.

Belyavin, G. (1951). J. gen. Microbiol., 5, 197.

Blair, J. E., and Carr, M. (1953). J. infect. Dis., 93, 1.

Davidson, I. (1961). Res. vet. Sci., 2, 396.

Dienes, L. (1946). Proc. Soc. exp. Biol. N.Y., 63, 265.

Eisenberg, G. M., Weiss, W., and Flippin, H. F. (1958). Amer. J. clin. Path., 30, 20.

Hill, G. A., Fung, J., and Marcus, S. (1962). J. Bact., 84, 191
Kippax, P. W. (1957). J. clin. Path., 103, 211.

Lishman, I. V., and Swinney, J. (1963). Brit. J. Urol., 35, 116.

Liu, P. V. (1958). Amer. J. clin. Path., 29, 176.

Milner, P. F. (1963). J. clin. Path., 16, 39.

Pavlatou, M., Hassikou-Kaklamani, E., and Zantioti, M. (1965). Ann. Inst. Pasteur, 108, 402.

Perch, B. (1948). Acta path. microbiol. scand., 25, 703.

Popovici, M., and Ghioni, E. (1962). Arch. roum. Path. exp., 21, 307.

Story, P. (1954). J. Path. Bact., 68, 55.

Ward-McQuaid, J. F. N. C., Jichlinski, D., and Macis, R. (1963). Brit. med. J., 2, 1311.

\section{The November 1967 Issue}

\section{THE NOVEMBER 1967 ISSUE CONTAINS THE FOLLOWING PAPERS}

Activation of lymphoctyes R. J. V. PULVERTAFT and ISOBEL PULVERTAFT

Lipofuscinosis of the gastrontestinal tract in man BERNARD FOX

Tracheopathia osteoplastica S. P. B. WAY

Acute necrotic myelitis and perivenous encephalomyelitis associated with hypertension and renal infection A. A. MILLER and F. RAMSDEN

Incidence and significance of argentaffin and Paneth cells in some tumours of the large intestine N. M. GIBBS

Significance and interpretation of laboratory tests in pulmonary aspergillosis MARY P. ENGLISH and A. $\mathrm{H}$. HENDERSON

Further observations on inclusion-bearing cells in urinary sediment in infectious diseases J. F. BOYD and NADA NEDELKOSKA

Granulomatous giant cell reticulosis associated with cases of treated leukaemia G. KRASZNAI, S. KERESZTURY, and L. SZüCS

Platelet adhesiveness in diabetes mellitus S. SHAW, (i. D. PEGRUM, SYLVIA WOLFF, and W. L. ASHTON

Red blood cell abnormalities in cardiac valvular disease J. FORSHAW and L. HARWOOD

Hyaline droplet formation in the renal epithelium of patients with haemoglobinuria s. J. BRYANT

Hyaline cast formation in patients treated with cephaloridine W. D. LINSELL, A. PINES, and J. W. HAYDEN

Observation on the levels of $\gamma \mathrm{G}, \gamma \mathrm{A}$, and $\gamma \mathrm{M}$ globulins, anti-A and anti-B agglutinins, and antibodies to Escherichia coli in Down's anomaly M. ADINOLFI, BRIGHITTE GARDNER, and WENDY MARTIN
Mycoplasmas and recurrent oral ulceration A. M. GORDON, H. M. DICK, D. K. MASON, W. MANDERSON, and W. B. CRICHTON

Resistance to cloxacillin among hospital staphylococcic G. C. TURNER and P. E. COX

Serological diagnosis of amoebiasis by immunofluorescence SOMNATE BOONPUCKNAVIG, and R. C. NAIRN

Evaluation of the fluorescent antibody technique for the diagnosis of smallpox A. L. A. EL-GANZOURY

Fatal transfusion reaction due to Serratia marcescens W. A. BLACK, A. POLLOCK, and ELIZABETH L. BATCHELOR

Importance of potency in typing by colicine production J. MCGEACHIE and W. MCCORMICK

Thyroid disease following the administration of Thorotrast A. O. LANGLANDS and KATE HERMANN

Use of diethylenetriamine penta-acetic acid (D.T.P.A.) in the clinical assessment of total body iron stores L. W. POWELL and M. J. THOMAS

Semi-automated method for the determination of free 3 fatty acids in plasma JOYCE D. BAIRD, M. W. BLACK, and D. E. FAULKNER

New automated method for measuring glucose by음 glucose oxidase D. G. CRAMP

\section{Technical methods}

Red cell volume distribution histograms for establishing the normal range using the Coulter plotter model $J_{N}$ $K$. CRAINE and A. D. WAFT

Measurement of red cell diameter by image shearingo P. N. COLEMAN

The Association of Clinical Pathologists: 79th generalब meeting

Book reviews

Index to volume 20 